\title{
Decision Support Concept to Selection of Wastewater Treatment Plant Location-the Case Study of Town of Kutina, Croatia
}

\author{
Nikša Jajac ${ }^{1}$, Ivan Marović ${ }^{2, * \mathbb{C}}$, Katarina Rogulj ${ }^{1}$ and Jelena Kilić ${ }^{1}$ \\ 1 Faculty of Civil Engineering, Architecture and Geodesy, University of Split, Matice hrvatske 15, 21000 Split, \\ Croatia; niksa.jajac@gradst.hr (N.J.); katarina.rogulj@gradst.hr (K.R.); jkilic@gradst.hr (J.K.) \\ 2 Faculty of Civil Engineering, University of Rijeka, Radmile Matejčić 3, 51000 Rijeka, Croatia \\ * Correspondence: ivan.marovic@gradri.uniri.hr; Tel.: +385-51-265-921
}

Received: 19 February 2019; Accepted: 3 April 2019; Published: 6 April 2019

check for updates

\begin{abstract}
In environmental projects, decision-making can be a complex and challenging task due to the in-built existence of compromises between environmental, socio-political, and economic factors. This paper explores a systematic approach to developing a decision support concept that includes the analysis of wastewater treatment problems, knowledge acquisition, and the identification and evaluation of criteria that bring forth an optimal solution to the location selection of wastewater treatment plants (WWTPs). The objective of this research is to develop a decision support concept (DSC) to aid in the planning phases of complex engineering projects, such as the construction of WWTP. The development of the concept starts with an assessment of the issue and an identification of relevant stakeholders accepting their different views and attitudes in an attempt to resolve this issue. The DSC was tested on a real case project-WWTP location selection within the town of Kutina, Croatia. Results indicate that it is possible to develop such a concept based on multicriteria methods on which decision-makers can rely.
\end{abstract}

Keywords: decision support concept; multiciteria decision-making; project management; planning; location selection; wastewater treatment plant

\section{Introduction}

The planning of a large and engineering-complex infrastructure project, especially in the area of wastewater drainage and disposal, is a very demanding task and the importance of decision support in this process is extensive. For these types of projects, i.e., environmental projects, it is necessary to identify and analyse various aspects, such as economic, ecological, structural-functional, socio-administrative, spatial, etc. They affect the planning process in order to achieve a long-term sustainability and, therefore, should be addressed accordingly. All aforementioned factors clearly show that project-planning depends on a large number of criteria mainly influenced and generated by the stakeholders. Therefore, quality planning must be based on a multicriteria approach to ensure that all the above-mentioned aspects of the problem are met.

The wastewater treatment plants (WWTPs) are designed in order to minimize the environmental impact of discharged sewage water into natural water systems. It is a known fact that different approaches of WWTP solutions have different performance characteristics as they directly impact the environment. Therefore, it is an imperative to minimize negative impacts on the environment as one of the main functions of wastewater treatment systems, which should be designed accordingly [1]. In addition to the protection of human health and surface waters, further goals of wastewater treatment systems should include minimizing the loss of resources, given the long-term needs for ecological sustainability, reducing the use of energy and water as well as reducing waste generation [2]. 
The concept presented in this paper is based on a model which a functionally-organized use of appropriate multicriteria decision-making methods together with the combination of their outputs, providing a quality background for investment planning. A response to setting requirements is the decision support system [3], which integrates the database, the model-base, and the knowledge-base subsystem to produce the required information, i.e., to support decision-making. More specifically, the aim of this research is to develop a decision support concept for the planning of a complex engineering project, such as the construction of wastewater treatment plants with a focus on selecting an optimal site location for its realization within a residential area. The concept is based on the application of two multicriteria methods: The Analytic Hierarchy Process (i.e., AHP) [4], and the Preference Ranking Organization Method for Enrichment Evaluations (i.e., PROMETHEE) [5], and their operational synergies [6]. Their synergic effect is used to compare and evaluate potential locations for constructing and modelling the recognition of all stakeholders' attitudes.

Specific goals of the paper are:

- To integrate various stakeholders and their opinions into a hierarchical goal structure,

- To develop a decision support concept (DSC) based on a multicriteria approach to aid in the planning phases of a complex engineering projects, and

- To test the developed concept on the real case study.

The paper is structured as follows: Firstly, the research background is introduced. Secondly, the methodology of the proposed concept is presented. Thirdly, the proposed concept is tested on a real case study, followed by results and discussion. Finally, the conclusions are drawn.

\section{Research Background}

As environmental issues concerning wastewater treatment are numerous, legislation is continuously revising the requirements for the level of removal of various pollutants in treated water. This often leads to a higher production of sludge. Pasqualino et al. [7] highlighted that the most sludge is traditionally disposed in landfill sites, incinerated with energy recovery, or dumped into the sea. For such purposes, various methods for evaluation of WWTPs' environmental impacts have been developed [8]. These methods are mostly of economic origin, such as Life Cycle Assessment (LCA), or methods based on LCA, Cost-benefit Analysis (CBA), and Data Envelopment Analysis (DEA).

Poch et al. [9] presented their findings, obtained over the last 10 years, in designing and building two real Environmental decision support systems (EDSSs): one for the wastewater plant supervision, and the other for the selection of wastewater treatment systems for communities with less than 2000 inhabitants. They highlighted the importance of dealing with complex environmental problems not only by developing tools for processing numerical aspects, but also by developing tools for gathering experience and knowledge from various experts. Gernaey et al. [10] highlighted the importance of white-box modelling in the field of wastewater treatment plants with learning, design, and process optimisation as the main applications. They give an advantage of this approach in relation to black-box modelling of the municipal wastewater systems. Assaf and Saadeh [11] provided an overview of the development and implementation of an integrated decision support system (DSS) designed to help policy makers and other stakeholders have a clearer understanding of the key factors and processes involved in the sewage-induced degradation of surface water quality. By the virtue of their DSS they have been able to formulate, assess, and evaluate alternative various management plans. Ceccaroni et al. [12] presented the architectural design of the decision support system for wastewater management, named OntoWEDSS. This system uses classic rule-based reasoning together with case-based reasoning, based upon domain ontology, thus providing a more flexible management capability. Hidalgo et al. [13] presented a multi-criteria analysis-based decision support tool for the promotion of safe reuse of the final effluent, while Garrido-Baserda et al. [14] assessed five alternative configurations for sludge treatment, in order to support the decision process and comparative purposes of reusing. Gomez-Lopez et al. [15] presented the use of a multicriteria based decision, by means of 
the Technique of Order Preference Similarity to the Ideal Solution (TOPSIS) method, applied to six different methodologies concerning the disinfection of treated wastewater before reuse. Hamouda et al. [16] reviewed approaches and methods used in decision support systems developed to aid in the selection, sequencing of unit processes, and design of various water treatment systems, such as drinking water, domestic wastewater, and industrial wastewater. Balkema et al. [17] developed a model-based decision support tool for the purpose of identifying the sustainable approaches to domestic wastewater treatment options. They based they sustainability approach on a multi-disciplinary set of indicators, including technical, economic, environmental, and socio-cultural aspects. Both approaches evolved from the decision support system developed for selecting the most appropriate small-scale wastewater treatment plant process for a given set of conditions (e.g., population and available budget for facility construction, operation and maintenance) [18].

The identification of adequate wastewater treatment for small communities, because of their special sensitivity to environment, is another segment of this complex problem. Therefore such approach demands a combination of data from different sources (both community and landscape) but also a knowledge of available wastewater treatment technologies. In 2005, Alemany et al. [19] considered using EDSS for the evaluation and identification of adequate wastewater treatment for 76 small communities located in the Fluvia River Basin. Similarly, Molinos-Senante et al. [20] combined such innovative EDSS with a pioneering approach based on the inclusion of the environmental benefits derived from wastewater treatment. Such an approach resulted in knowledge of economic feasibility indicators for each technology and the benefits associated with the environmental damage. Their approach proved to be crucial for supporting the decision process by improving the sustainability of new treatment plants and at the same time having selected the most feasible and up-to-date technologies.

Throughout the years, different approaches and models that allow the improvement of management and the sustainability assessment of wastewater treatment, maintenance, and renewal have been proposed [21-30]. Mostly, the researchers dealt with the various aspects of the knowledge-based subsystem of the DSS, focusing on implementing environmental aspects to the problem. In addition to these papers there are those proposing similar methodological approaches derived for different kinds of problems and for different fields of interests, but with the same purpose, improvement of sustainable managerial decision-making [31-34]. These researchers dealt with additional aspects of developing and implementing a compromised view of all involved stakeholders into decision-making processes.

For each of the aforementioned aspects of the problem, sets of criteria have been developed to evaluate potential locations, and in the process of this evaluation, it is necessary to include all stakeholders involved throughout the project, from its realization to exploitation. This approach provides a higher level of information to the general public about the problem and the processes of its realization, and ultimately provides a simpler implementation of the project. Namely, it reduces the overall level of stakeholder's uncertainty regarding solving and selecting a solution for the final location. As the complexity of these tasks increases, the number of decision-makers increases accordingly. As a result, the decision-making process becomes more complex, and if there is no systematic approach and decision support, there will certainly be inconsistencies in decision-making.

In the follow-up of this paper, the concept of decision support will be presented with the example of planning the construction of WWTP in the town of Kutina, Croatia.

\section{Materials and Methods}

\subsection{Decision Support Concept to Resolving the Problem of Location Selection}

The concept of the proposed decision support is shown in Figure 1. The application of this concept begins with the determination and gathering of all stakeholders' groups. Stakeholders are divided into three groups: city government representatives (i.e., city government), experts in the field of civil engineering, architecture and geodesy, as well as environment (i.e., experts), and local end-users (i.e., citizens), as shown in the left rectangle in Figure 1. The first stakeholders' activity is to define the main 
goal, its objectives, and the criteria that form the goal hierarchical structure. Stakeholders from all three groups are involved in defining the main goal, while other objectives in the hierarchy as well as the criteria are determined solely by the each expert stakeholder group. By setting up a hierarchical structure, all relevant aspects of the problem when choosing a location are defined.

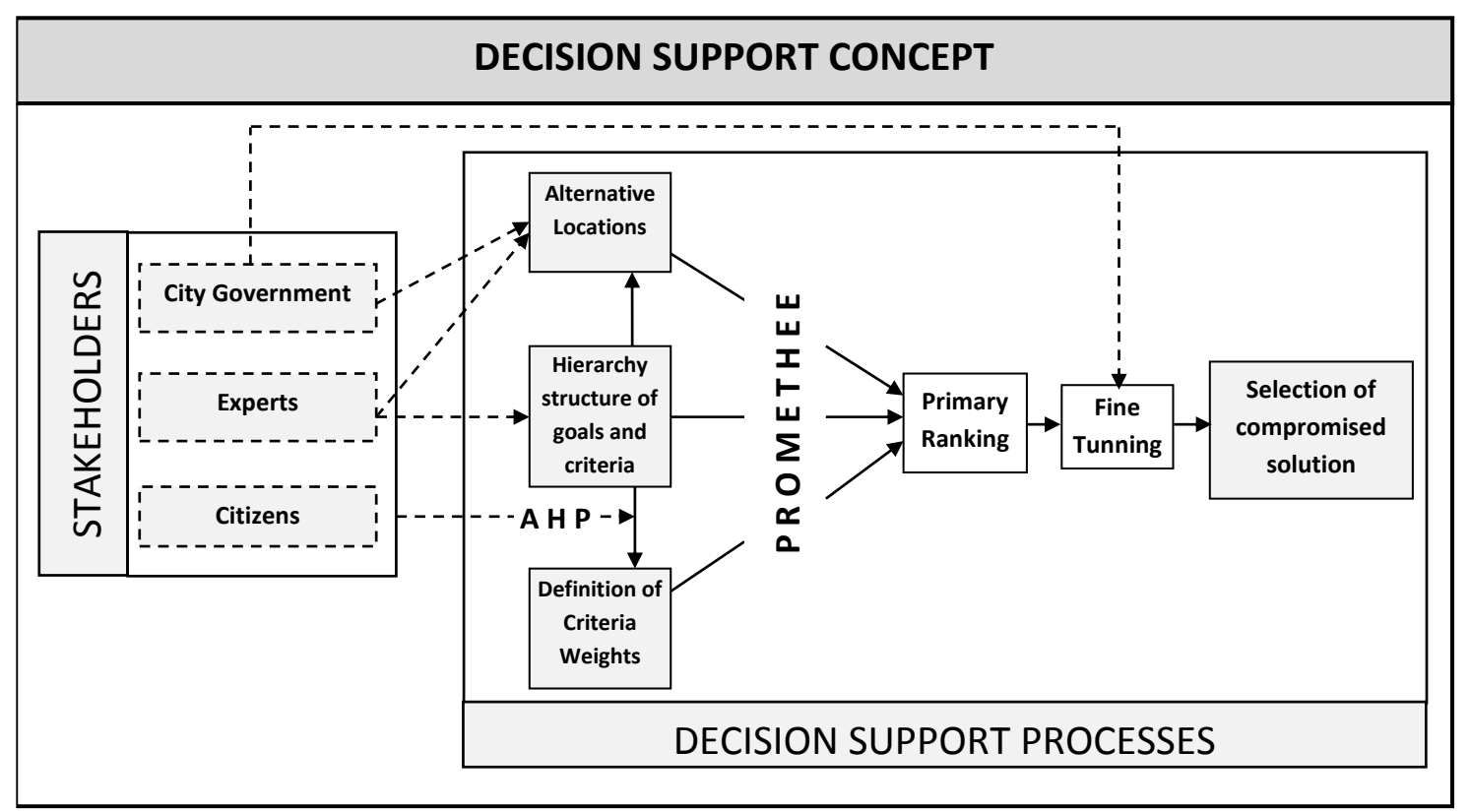

Figure 1. Decision support concept for location selection of wastewater treatment plants.

The realization of objectives eventually means that the main goal will be achieved. Each of the objectives has its own sub-objectives. Branching, or the establishment of a hierarchical structure, of the sub-objectives continues to a level where they can no longer be divided into their sub-objectives, and end up at the bottom of the hierarchical structure. The sub-objectives at the lowest level are set to measure their achievement (evaluation of alternative solutions), which eventually defines the criteria. Ingenious objectives can be divided into more sub-objectives. The following arguments refer to the defining of alternative solutions and the importance of established criteria pertaining to the given problem of finding the optimal location for the treatment device. Alternative solutions for this problem are also included as possible locations for the construction of a wastewater treatment plant. Defining alternative locations is decided based upon two groups of stakeholders. The first group are experts for wastewater treatment and spatial planning (spatial planners) and the other are city government representatives. All stakeholder groups participate in determining the importance of the criterion using the AHP method. Each group sets one set of criteria weight. The fourth set of criteria weights is derived from the average weight values of each of the criteria from the three scenarios that will be further used.

For each criterion, preference functions should also be specified. These functions describe how to determine the intensity of preference, i.e., how to gain a preference for one solution over the others by the decision maker according to the criterion to which it is assigned [35]. In other words, the preference function determines the intensity of the decision-maker's preference for one solution according to the others by a single criterion. The intensity of preference is determined by the calculated differences in the ratings of the solution according to this criterion [36]. Then, all alternative solutions are evaluated according to each criterion. Using the obtained grades within a decision matrix, the chosen preference function, and criteria weights, a multicriteria model with the engagement of the PROMETHEE II method is formed. The results that are obtained by comparing the alternatives become the complete ranking of the analysed solutions. Such a ranking takes into account the views of all stakeholders; therefore, it is a compromised solution and serves as a basis for decisions by the investor's 
representatives (representatives of the city administration/mayor or person in charge of making such decisions in the city or municipal utility company) [33,37].

The next step is to involve only representatives from the city administration, i.e., the formal, legitimate, and, ultimately, legally responsible decision-makers in the process of selecting the location by changing the individual weighing of criteria (e.g., Walking Weights Functionality) and by following the changes in the results depending on the weight of criteria. The representative of the city administration in this way performs the so-called fine tuning. When the investor is satisfied with the criteria weights and the final ranking, he/she can approach the final step and select the compromised solution.

In Figure 1, the left rectangle shows the structure of stakeholders that is proposed for this concept, and the right rectangle shows the processes needed to take place during the application of the concept, as well as their interactions. Full lines precisely mark those functional interactions between processes while the intercepting lines show the involvement of stakeholders within the different processes of the concept.

With this approach, it is possible to improve the level of investment planning in the urban communal infrastructure area. This concept is applicable to a variety of possible projects of urban environment management, generally in the field of construction, especially infrastructural projects. This concept is adaptable to all conditions of life organizing within individual residential areas, as well as the investor's management style.

\subsection{Multicriteria Methods}

The methods and techniques of Multicriteria Decision-Making (MCDM) are derived from the early 1980s and are used as a tool for solving complex decision-making problems. The MCDM often deals with the ranking of many concrete alternatives from the best to the worst ones based on multiple-conflicting criteria. Throughout the years, many MCDM methods have been proposed by researchers and practitioners. However, some of them, such as AHP, PROMETHEE, ELECTRE (ELimination Et Choix Traduisant la REalite), and ORESTE (Organization Rangement Et Synthese De Donnes Relationnelles) [38], have been widely accepted because of their capability to adjust to a variety of problems and user-friendliness, while Hazir [39] gave an overview of analytical models, approaches, and decision support tools in monitoring and control processes during project management in construction. Mendoza et al. [40] highlighted that in a situation where multiple criteria are involved, and MCDM methods are used, a confusion can arise if a logical and well-structured decision-making process is not obeyed. Moreover, they emphasised that reaching a general consensus in a multidisciplinary team can be very difficult to achieve. In this study, AHP and PROMETHEE have been used, as they complement each other very well $[28,30,31]$. Therefore, their brief descriptions are given in the following sections.

\subsubsection{The AHP Method}

The AHP method was developed by Saaty [4]; this method comprises a set of evaluation criteria and alternative options, from which the best decision is derived. It is particularly useful when the decision-maker is unable to construct a utility function. In order to be used, a decision-maker needs to structure a desired problem and set priorities. Instead of providing a numerical judgement, a decision-maker need to provide a verbal appreciation of criteria. He/she generates a weight for each evaluation criterion (both qualitative and quantitative) according to the decision-makers' pairwise comparisons of the criteria. The higher the weight, the more important the corresponding criterion.

The AHP combines the criteria weights and the option scores, thus determining a global score for each option, and consequently a final ranking. The computations made by the AHP are always guided by the decision maker's experience, and the AHP can only be considered a helping tool and cannot replace a decision-maker. Therefore, the AHP method can be seen as a simple tool because there is no need to build a complex expert system with the decision maker's knowledge embedded in it. 
In order to compute the weights for different criteria, the AHP starts creating a pairwise comparison matrix A. The matrix A is an $m \times m$ real matrix, where $m$ is the number of evaluation criteria considered. Each entry $a_{j k}$ of matrix A represents the importance of the $j$ th criterion relative to the $k$ th criterion. If $a_{j k}>1$, then the $j$ th criterion is more important than the $k$ th criterion, while if $a_{j k}<1$, then the $j$ th criterion is less important than the $k$ th criterion. If two criteria are of equal importance, then the entry $a_{j k}$ is 1 . The entries $a_{j k}$ and $a_{k j}$ satisfy the following constraint:

$$
a_{j k} \times a_{k j}=1
$$

where, observably, $a_{j j}=1$ for all $j$. The relative importance between two criteria is measured according to a numerical evaluation scale [4], where it is assumed that the $j$ th criterion is equally or more important than the $k$ th criterion. The values in the matrix A are by constructing a pairwise constant. Once the matrix $\mathrm{A}$ is built, it is possible to derive from $\mathrm{A}$ the normalized pairwise comparison matrix $\left(\mathrm{A}_{\text {norm }}\right)$ when the sum of the entries in each column reach the value of 1 , i.e., each entry $\overline{a_{j k}}$ of the matrix $\left(\mathrm{A}_{\text {norm }}\right)$ is computed as:

$$
\overline{a_{j k}}=\frac{a_{j k}}{\sum_{l=1}^{m} a_{l k}}
$$

Finally, the criteria weight vector $w$ (that is, an $m$-dimensional column vector) is built by averaging the entries on each row of the normalize matrix:

$$
w_{j}=\frac{\sum_{l=1}^{m} \overline{a_{j k}}}{m}
$$

It is very easy to assign weights of criteria through the group decision-making process using this method. However, the AHP, along with the suggested alternatives, are transfigured into criteria that are further used in this study to assess the ranking of optimal locations for WWTP. For the purpose of the developed DSC, the AHP method is used to evaluate the goal hierarchy, i.e., to set weights for all identified criteria by the virtue of all stakeholder groups.

\subsubsection{The PROMETHEE Method}

The PROMETHEE method was developed by Brans, Mareschal, and Vincke [5] and is widely-accepted among decision-makers. It is comprehensive and has the ability to present results using a simple ranking. It makes a comparison throughout the decision matrix and ranks various alternatives that are, at the same time, valued on the basis of several quantitative or qualitative criteria.

A matrix, consisting of a set of potential alternatives $A$, serves as input data for the PROMETHEE methods (respectively PROMETHEE I and PROMETHEE II). Each $a$ element of $A$ is $f(a)$ which represents the evaluation of one criterion and each evaluation $f_{i}\left(a_{i}\right)$ must be a real number. The PROMETHEE I gives a partial ranking and then from the PROMETHEE II method, which gives the complete ranking of actions, a net outranking flow is obtained $[33,38,41]$ :

$$
\Phi(\mathrm{a})=\Phi^{+}(\mathrm{a})-\Phi^{-}(\mathrm{a})
$$

where $\Phi^{+}(\mathrm{a})$ is the positive outranking flow and is defined as:

$$
\Phi^{+}(\mathrm{a})=\frac{1}{n-1} \sum_{x \in A} \prod(a, x)
$$

and $\Phi^{-}$(a) is the negative outranking flow, which is defined as:

$$
\Phi^{-}(\mathrm{a})=\frac{1}{n-1} \sum_{x \in A} \prod(x, a)
$$


where $a$ and $x$ are the actions from the set of actions $A$ (during the pairwise comparison of action $a$ with all other $n-1$ actions), $n$ represents the number of actions, and $\Pi$ is the preference index defined for each pair of actions:

$$
\prod(a, b)=\frac{\sum_{j=1}^{m} w_{j} P_{j}(a, b)}{\sum_{j=1}^{m} w_{j}}
$$

where $P_{j}(a, b)$ represents preference of $a$ over $b$ for a given preference function of criterion $j$, and $w_{j}$ is a weight of criterion $j$. Since $\sum_{j=1}^{m} w_{j}=1$, Equation (7) changes its expression into: $\prod(a, b)=\sum_{j=1}^{m} w_{j} P_{j}(a, b)$.

There are six types of preference functions proposed by the authors of the method $[5,41]$ thus giving the opportunity to both the analyst and the decision-maker to choose, in mutual agreement, one of PROMETHEES' six predefined preference functions (Usual, U-shape, V-shape, Level, Linear, or Gaussian) for each criterion, with regard to their knowledge about intensity and direction of preference.

In each particular case, certain parameters should be determined in advance, as each parameter comes with a real economic meaning. Different sets of criteria weights can be used to create a unique scenario, as well. The subsequent weight of each criterion can be perceived as a compromised weight, which can be interpreted as a compromised view of the problem that respects the views of different stakeholders equally. Therefore, the stakeholders' attitudes are expressed through the weights assigned to the criteria and selected preferences functions. For the purpose of developed DSC, the PROMETHEE II method was used to rank all identified alternatives, i.e., site locations according to stakeholders' compromised weights of all identified criteria.

\section{Results and Discussion}

Since this paper proposes a new decision support concept to select a wastewater treatment plants' location, it is necessary to validate it. The concept was tested on the real case project with the problem of the location selection for the construction of WWTP in the town of Kutina, Croatia. The Project manager from planning to construction was a local municipal company under the authority of Kutina. The proposed concept represents the support of the municipal company in project management during the project planning stage. Application of the concept assists the decision-maker in the process of selecting a compromise solution. Figure 2 presents the urban plan of the town of Kutina and its three potential locations for a wastewater treatment plant.

Validation of the concept begins by defining stakeholder groups and members of each stakeholder group. Three groups are defined. The first group consists of experts (wastewater treatment experts, civil engineering and spatial planning experts, project management infrastructure experts, experts on environmental issues, human health and ecology, socio-economic experts, and multi-criteria experts who give operative support during usage of the concept). The second group consists of decision-makers' representatives, i.e., representatives of the local government and municipality companies (mayor and director of municipal company). The third group presents the attitude of local population representatives, and future end-users (city council members and representatives of city quarters, i.e., districts).

The next step is the establishment of the goal hierarchical structure. Determining the main goal is the task of all stakeholders' groups and is: "The best location for a wastewater treatment plant." Furthermore, only the expert groups deal with the definition of objectives on all hierarchical levels. Eventually, they define the criteria. The expert group was informed about the task in advance (the choice of the location for the wastewater treatment plant). The investor (in this case, the municipal company) decided that the same treatment plant (in terms of use, dimensions, structural features, and standard equipment) will be built on each of the proposed locations. That was done because the construction of the treatment device, regardless of location, can solve the problem of wastewater treatment for the entire town of Kutina. This approach ensures comparability of proposed locations 
and draws attention to the impact of their features concerning the project realization, but also takes into account the need to improve the quality of life in Kutina by constructing the device.

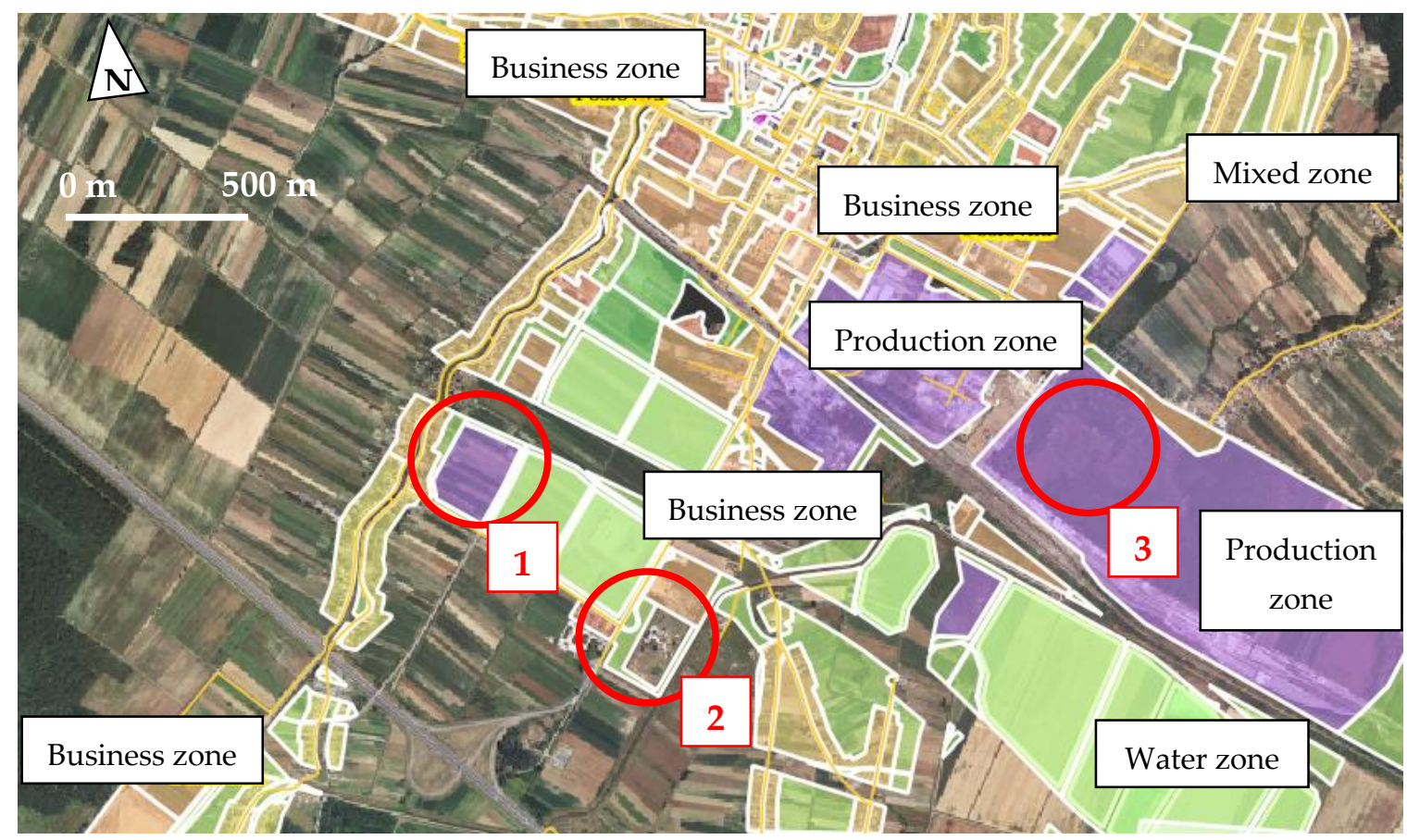

Figure 2. Town of Kutina-General Urban Plan and potential locations.

The stakeholders start with the definition of the first level objectives and then the second level, where its purpose is to support the first level objectives and, incidentally, the main goal. Objectives from the second level are, in this case, indivisible and will be used as criteria for evaluating alternative solutions. They are used to evaluate the intensity of the completion of different aspects of each alternative solution in order to achieve the main goal. Moreover, by using them, these alternative solutions will be evaluated. Figure 3 shows the generic hierarchical goal structure proposed for future project planners in solving the problem of location selection for a wastewater treatment plant in a residential area. This simple structure can be expanded upon, depending on the needs and specifics of a particular project problem.

The first level objectives are: maximization of technological aspects, maximization of socio-economic aspects, and maximization of ecological aspects. From Figure 3, it can be seen that all objectives have their supportive sub-objectives (criteria) that make up the second level of hierarchy. There are 13 criteria that are labelled with $\mathrm{Cn}$, where $\mathrm{n}=1, \ldots, 13$, divided into three different groups, i.e., objectives. When defining sub-objectives (criteria) for each of the first level objectives, an expert group must be established. Thus, technological experts define criteria $\mathrm{C} 1, \mathrm{C} 2, \mathrm{C} 3$, and $\mathrm{C} 4$, socio-economic experts define the criteria $\mathrm{C} 5, \mathrm{C} 6, \mathrm{C} 7, \mathrm{C} 8$, and $\mathrm{C} 9$, while environmental experts define the criteria $\mathrm{C} 10, \mathrm{C} 11, \mathrm{C} 12$, and $\mathrm{C} 13$.

For the purpose of clarity and visibility, only criteria labels are shown in Figure 3, while a full description of each criteria is presented in Table 1 together with its $\mathrm{min} / \mathrm{max}$ direction and the type of preference function. Preference functions represents a way for a decision-maker to establish his/her preferences between two proposed locations for the wastewater treatment plant. In this case, the decision-maker chose to use two types of preference functions (V-shape and Linear preference functions) that are best suited for quantitative criteria. The choice of only two types of preference functions solely depends on the characteristics of the identified criteria and whether he/she wants to introduce a threshold or not. Furthermore, thresholds for these functions are not introduced because engaged 
experts and decision-makers consider that there is importance in criteria evaluation, even when there is a slight difference in the evaluation of proposed construction sites locations.

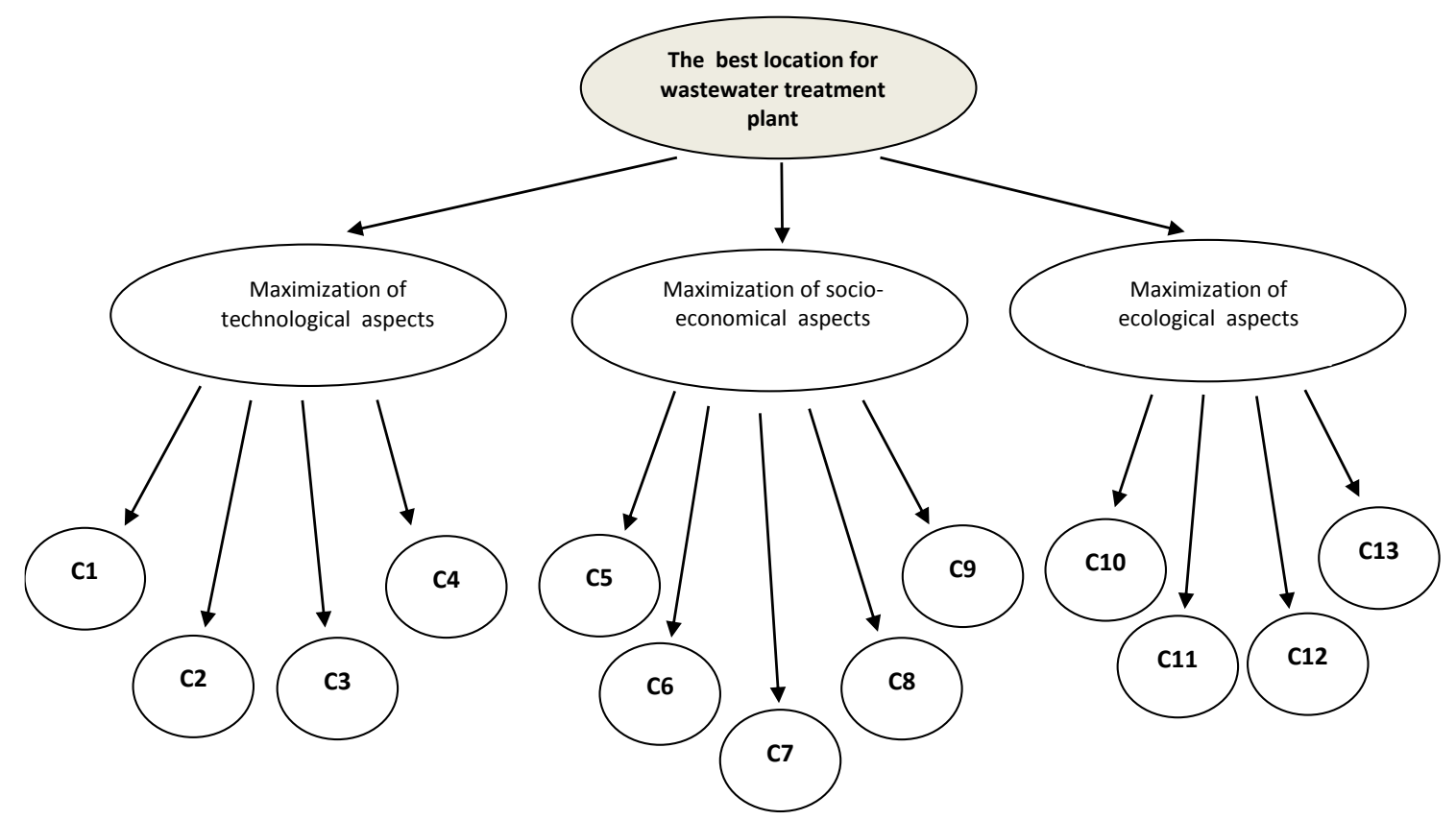

Figure 3. Hierarchical structure of goals and criteria.

Table 1. Criteria-labels, names, short descriptions, and preferences. WWTP, wastewater treatment plant.

\begin{tabular}{|c|c|c|c|c|}
\hline \multirow[b]{2}{*}{ Criteria Label } & \multirow[b]{2}{*}{ Criteria Name } & \multirow{2}{*}{$\begin{array}{c}\text { Short Description of Criteria, and } \\
\text { Technique Used for the Evaluation of } \\
\text { Alternative Locations }\end{array}$} & \multicolumn{2}{|c|}{ Preference } \\
\hline & & & Min/Max & Function \\
\hline $\mathrm{C} 1$ & Constructability & $\begin{array}{l}\text { Expert assessment related to excavation } \\
\text { and foundation works-grading: } 0 \\
\text { (worst)-10 (best) }\end{array}$ & $\max$ & V-shape \\
\hline $\mathrm{C} 2$ & $\begin{array}{l}\text { Construction } \\
\text { time/launch of } \\
\text { exploitation }\end{array}$ & $\begin{array}{l}\text { Expected duration of construction } \\
\text { works according to Construction } \\
\text { management plan (dynamic } \\
\text { plan)_grading: number of months }\end{array}$ & $\min$ & Linear \\
\hline $\mathrm{C} 3$ & $\begin{array}{l}\text { Quality of utility } \\
\text { infrastructure }\end{array}$ & $\begin{array}{c}\text { Experts' assessment of existence and } \\
\text { quality of all types of utility } \\
\text { infrastructure (water supply system, } \\
\text { sewage system, electrical system and } \\
\text { waste management system) in } \\
\text { surrounding area in terms of the } \\
\text { possibility of their connection to the } \\
\text { wastewater treatment plant-grading: } 0 \\
\text { (worst)-10 (best) }\end{array}$ & $\max$ & V-shape \\
\hline $\mathrm{C} 4$ & $\begin{array}{l}\text { Proximity of } \\
\text { landfill for } \\
\text { excavation material }\end{array}$ & $\begin{array}{l}\text { Expert assessment that takes into } \\
\text { account landfill proximity according to } \\
\text { Construction management plan } \\
\text { (technological plan)—grading } 0 \\
\text { (worst)-10 (best) }\end{array}$ & $\max$ & V-shape \\
\hline $\mathrm{C} 5$ & $\begin{array}{l}\text { Time required to } \\
\text { obtain building } \\
\text { permits }\end{array}$ & $\begin{array}{l}\text { Expert assessment of expected time to } \\
\text { obtain building permits-grading: } \\
\text { number of months }\end{array}$ & $\min$ & Linear \\
\hline
\end{tabular}


Table 1. Cont

\begin{tabular}{|c|c|c|c|c|}
\hline \multirow{2}{*}{ Criteria Label } & \multirow{2}{*}{ Criteria Name } & \multirow{2}{*}{$\begin{array}{l}\text { Short Description of Criteria, and } \\
\text { Technique Used for the Evaluation of } \\
\text { Alternative Locations }\end{array}$} & \multicolumn{2}{|c|}{ Preference } \\
\hline & & & Min/Max & Function \\
\hline C6 & Value of property & $\begin{array}{l}\text { The amount corresponding to the } \\
\text { market value of assessed } \\
\text { location—grading: EUR } / \mathrm{m}^{2}\end{array}$ & $\min$ & Linear \\
\hline $\mathrm{C} 7$ & $\begin{array}{l}\text { Integration into } \\
\text { urban plans }\end{array}$ & $\begin{array}{c}\text { Expert assessment regarding fact that } \\
\text { the building is recorded into spatial } \\
\text { plans (e.g., city general urban plan, } \\
\text { master plan) or not and needs to be } \\
\text { recorded-grading: } 0 \text { (not recorded) or } \\
1 \text { (recorded) }\end{array}$ & $\max$ & / \\
\hline $\mathrm{C} 8$ & $\begin{array}{l}\text { Property } \\
\text { ownership }\end{array}$ & $\begin{array}{l}\text { Defines whether the land is owned by } \\
\text { local government units (LGUs) or } \\
\text { not-meaning land needs to be } \\
\text { purchased from one or more private } \\
\text { owners-grading: } 0 \text { (private } \\
\text { ownership) or } 1 \text { (owned by LGUs) }\end{array}$ & $\max$ & / \\
\hline C9 & $\begin{array}{c}\text { Attractiveness of } \\
\text { location }\end{array}$ & $\begin{array}{l}\text { Expert assessment that takes into } \\
\text { account decrease of attractiveness of the } \\
\text { surrounding area of the potential plant } \\
\text { location in terms of reduced quality of } \\
\text { life and business to the existing } \\
\text { situation within the area-grading: } 0 \\
\text { (worst- maximal decrease)-10 } \\
\text { (best-minimal decrease) }\end{array}$ & $\max$ & V-shape \\
\hline $\mathrm{C} 10$ & $\begin{array}{l}\text { Sensitivity of the } \\
\text { surrounding area } \\
\text { to noise pollution }\end{array}$ & $\begin{array}{l}\text { Expert evaluation which takes into } \\
\text { account the appropriate proximity from } \\
\text { the residential area (especially near day } \\
\text { care facilities and hospitals) and } \\
\text { population density (concerns of } \\
\text { people's welfare especially children and } \\
\text { health-sensitive citizens) - grading: } 0 \\
\text { (less sensitive)-10 (very sensitive) }\end{array}$ & $\min$ & V-shape \\
\hline $\mathrm{C} 11$ & $\begin{array}{l}\text { Sensitivity of the } \\
\text { surrounding area } \\
\text { to exhaust } \\
\text { emissions }\end{array}$ & $\begin{array}{l}\text { Expert evaluation which takes into } \\
\text { account the appropriate proximity from } \\
\text { the residential area (especially near day } \\
\text { care facilities and hospitals) and } \\
\text { population density (concerns of } \\
\text { people's welfare especially children and } \\
\text { health-sensitive citizens) - grading: } 0 \\
\text { (less sensitive)-10 (very sensitive) }\end{array}$ & $\min$ & V-shape \\
\hline $\mathrm{C} 12$ & $\begin{array}{l}\text { Quantity of } \\
\text { wastewater } \\
\text { transportation in } \\
\text { daily use }\end{array}$ & $\begin{array}{l}\text { Expert assessment of pollution } \\
\text { reduction (exhaust and noise) } \\
\text { generated by the transportation of } \\
\text { wastewater (from septic tanks) due to } \\
\text { the construction of WWTP. Assessment } \\
\text { is taking into account changes in } \\
\text { driving distance (duration of driving } \\
\text { cycle) to the future WWTP, quantity } \\
\text { and frequency of wastewater } \\
\text { transportation-grading: } 0 \text { (minimum } \\
\text { reduction)-10 (maximal reduction) }\end{array}$ & $\max$ & V-shape \\
\hline $\mathrm{C} 13$ & $\begin{array}{l}\text { Connectivity of the } \\
\text { major wastewater } \\
\text { generators }\end{array}$ & $\begin{array}{l}\text { Expert estimates that determine the } \\
\text { degree of availability for the connection } \\
\text { of large generators of wastewater } \\
\text { (primarily industrial plants) to future } \\
\text { WWTP-grading: } 0 \text { (low degree)-10 } \\
\text { (high degree) }\end{array}$ & $\max$ & V-shape \\
\hline
\end{tabular}


The importance of each criterion is given throughout the weights of the criteria and was determined separately by each group of the stakeholders. In this way, three scenarios of the same problem are created and analysed as follows: experts (SC1), city government (SC2), and citizens (SC3). For such purposes, the AHP method has been used to determine the weights of the criteria at each scenario, due to its simplicity and ease of use.

The AHP method is used to determine the importance of the criteria at the lower level in the achievement of an objective from the higher level (see Figure 3), starting from the top of the goal hierarchy structure (the main goal level), through the mid-level (the objective level), to the bottom (the criteria level). The weight of each criterion is expressed by its percentage of the total weight of all criteria, which is $100 \%$, and is presented for each scenario in Table 2. At the criteria level, experts are given the possibility to express their opinion toward criteria by pairwise comparison.

Table 2. Criteria weights each stakeholder scenario (SC1-3) and a compromised scenario (SC4).

\begin{tabular}{cccccccccccccc}
\hline & \multicolumn{10}{c}{ Criteria } \\
\hline Scenarios & C1 & C2 & C3 & C4 & C5 & C6 & C7 & C8 & C9 & C10 & C11 & C12 & C13 \\
\hline SC1 & 0.100 & 0.100 & 0.150 & 0.100 & 0.040 & 0.070 & 0.080 & 0.070 & 0.050 & 0.050 & 0.050 & 0.040 & 0.100 \\
SC2 & 0.040 & 0.070 & 0.040 & 0.050 & 0.040 & 0.160 & 0.160 & 0.140 & 0.050 & 0.050 & 0.050 & 0.050 & 0.100 \\
SC3 & 0.030 & 0.030 & 0.030 & 0.040 & 0.030 & 0.080 & 0.080 & 0.030 & 0.150 & 0.150 & 0.150 & 0.150 & 0.050 \\
SC4 & 0.057 & 0.067 & 0.073 & 0.063 & 0.037 & 0.103 & 0.107 & 0.080 & 0.083 & 0.083 & 0.083 & 0.080 & 0.083 \\
\hline
\end{tabular}

Regarding expressed conflicts between the scenarios, compromised weights are found by calculating the simple average of scenarios' weights, thus giving equal importance to all groups of stakeholders. The new fourth scenario (the last row in Table 2) is formed with these compromised weights and considered the best one for following ranking process.

The weight distributions for the first three scenarios (shown in Table 2) are as expected. Specifically, experts regard those criteria that give importance to the engineering aspects of the problem, namely, $\mathrm{C} 1$ to $\mathrm{C} 4$, but the most important is C3-The quality of utility infrastructure. Likewise, the most important criteria to the city government stakeholders is considered C5 to C9, especially C6-Value of property and C7-Property ownership, which are related to the evaluation of the financial aspects of the project. the citizen group pointed out criteria from $\mathrm{C} 10$ to $\mathrm{C} 13$ as the most important, particularly C10-Sensitivity of noise pollution emitted from the plant, C11-Sensitivity to exhaust emissions emitted from the plant to the surrounding area, and C12-Quantity of wastewater transport trucks in daily use. These criteria take part in the evaluation of the ecological aspects of the WWTP impact for each potential location, thought they consider criteria from C5 to C9 important as well, especially C9-The attractiveness of the location, because of their socio-economic nature.

Table 3 shows the multicriteria model (decision matrix) for the primary priority ranking of locations for the realization/construction of the WWTP project within the town of Kutina. The compromised weights values (the last row of Table 2) are used in multicriteria method as criteria weights values (as shown in Table 3).

Table 3. Multicriteria model.

\begin{tabular}{|c|c|c|c|c|c|c|c|c|c|c|c|c|c|}
\hline \multirow{2}{*}{$\begin{array}{l}\text { Location } \\
\text { Code }\end{array}$} & \multicolumn{13}{|c|}{ Compromised Criteria Weights } \\
\hline & $\mathrm{C1}$ & $\mathrm{C} 2$ & $\mathrm{C3}$ & $\mathrm{C} 4$ & $\mathrm{C5}$ & C6 & $\mathrm{C7}$ & $\mathrm{C8}$ & C9 & C10 & C11 & $\mathrm{C} 12$ & C13 \\
\hline & 0.057 & 0.067 & 0.073 & 0.063 & 0.037 & 0.103 & 0.107 & 0.080 & 0.083 & 0.083 & 0.083 & 0.080 & 0.083 \\
\hline L1 & 5 & 20 & 6 & 8 & 7 & 45 & 0 & 0 & 1 & 7 & 7 & 6 & 1 \\
\hline L2 & 9 & 18 & 4 & 7 & 12 & 30 & 1 & 1 & 5 & 6 & 6 & 2 & 5 \\
\hline L3 & 10 & 14 & 9 & 6 & 6 & 20 & 1 & 1 & 10 & 4 & 3 & 9 & 10 \\
\hline
\end{tabular}

Therefore, the decision matrix of the proposed multicriteria model consists of 13 columns (criteria) and 3 rows (alternatives). Each column gives an evaluation of possible alternatives i.e., WWTP locations 
regarding a single criterion, while the assessment of all alternatives across all observed criteria is presented in the rows.

By using software Visual PROMETHEE (http://www.promethee-gaia.net), the presented data of decision matrix were subjected to a ranking process with the usage of the multicriteria method PROMETHEE II, and primary priority ranking was generated for the mentioned locations for the WWTP. The set of data within the decision matrix, which is shown in Table 3, was prepared (normalized and transformed) before the implementation of the PROMETHEE II method. Since this method provides ranking by mutual comparison of all locations with every criterion holding, with respect to the stakeholders' attitudes, it resulted in a complete ranking of observed alternatives. As shown in Figure 4, the results of the applied method PROMETHEE II were presented to city government representatives. Location 3 has the best ranking, significantly better than the other two locations. The difference between the first and second ranked locations is 0.0604 , while difference between the rankings of Location 2 (2nd ranked) and Location 1 (3rd ranked) is 0.0299. It is a significantly lesser difference than the difference between the first and second ranked locations. Location 1 was the worst ranked location.

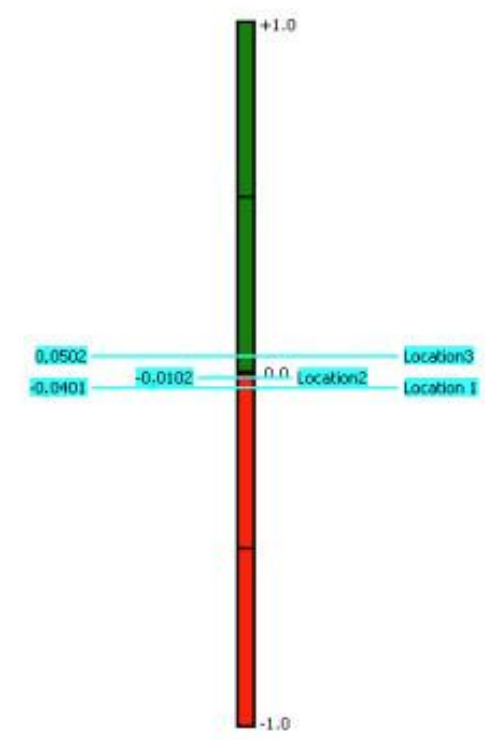

Figure 4. Results of PROMETHEE II-complete ranking.

Stability intervals were presented to city government representatives. All of the above were done to provide the city representative better insight into the possibilities of their own impact on the final ranking, while he/she conducted fine tuning (i.e., Walking Weights).

During fine tuning, the city representative decided to increase the weights of the following criteria: C6 (Value of property), C7 (Integration into urban plans), and C8 (Property ownership), and at the same time, reduced the weights of the criteria C1 (Constructability) and C2 (The time required for construction/until the start of exploitation). This process created new weight values in the hierarchical goal structure. By doing so, it is important to perform sensitivity analysis and observe a stability interval of the primary weights in order not to change scores and ranking. The new weight values (i.e., the final weights) did not led to a change in the ranking, presented in Figure 4, but the differences between the second and third placed alternatives had grown, making their new value 0.1101. Regardless of the significant change of difference (0.0802) between the second and third ranked locations, the difference between the first and second ranked locations has undergone minor change, with a reduction of 0.0139 , and now is valued at 0.0465 .

The Figure 5 shows the final criteria weights and the final ranking of solutions for location of WWTP is as follows: 1st is Location 3, 2nd is Location 2, 3rd is Location 1. 

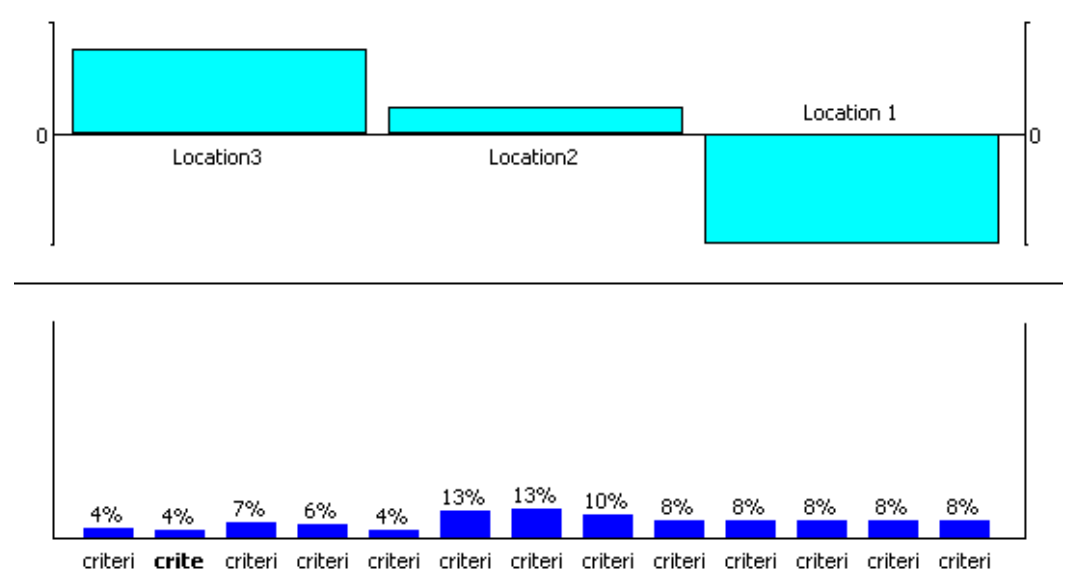

Figure 5. Final ranking of investment solutions and fine-tuned criteria weights.

According to the results of "fine tuning", one of three alternatives for the location of the future WWTP should be included in the investment plans of town of Kutina for the following investment cycle. The city government has decided to implement this project for the future WWTP at Location 3.

The ineffectiveness of the collaboration of various, and often opposing, stakeholder attitudes and desires will lead to the decay of the decision-making process, whether it is a complete abandonment of the project or an insufficient quality solution (i.e., location selection) due to the dominance of a particular stakeholder group or even individuals. It often happens that the arguments of a dominant stakeholder lead to the selection of unsustainable solutions, even when they are clearly in opposition with realistic expert assessments of possible opportunities. In order to avoid this problem, a new concept of decision support in the planning process of the location selection is proposed for the realization of such a sensitive project. Moreover, experts suggest that these processes, when creating engineering solutions, must meet the needs of the broader community as much as possible. Previous studies $[31,33,34,36,37]$ give insight into forming compromise solutions as an important part of a multicriteria approach in construction project management. Such a compromise resulted in a strict hierarchical goal structure at the beginning of decision process. The novelty of the proposed approach is the "fine tuning" opportunity given to the decision-maker. In this case, the relevant stakeholders are divided into several groups, such as a group of experts in the area related to wastewater treatment and spatial planning, the representatives of local government, and the representatives of end-users (i.e., local population). The application of this approach gives a thorough analysis of the problem, as it involves the opinions and evaluations of all stakeholders. Through this concept, relevant data and information from all segments of the future project implementation are processed. This concept serves as an aid to the decision-maker, but does not replace him/her in the decision-making process. The final decision will set important determinants for engineering design solutions. The better the decision is defined, the simpler it will be to find the engineering solution and its implementation into the environment.

\section{Conclusions}

By applying the proposed decision support concept, it is possible to overcome most of the problems encountered when solving poorly structured and/or semi-structured problems that often occur in the planning stages of construction projects, such as the selection of the construction site location. Some of the problems that arise are the result of commonly conflicting criteria that come from critical stakeholders and their various opinions. A multicriterial approach to this problem gives various opportunities to describe and involve different stakeholders consistently into strategic planning, thereby resulting in a compromise solution to the desired problem, i.e., location selection. The unique and comprehensive gathering of obtainable and relevant data, together with its processing and presentation of results to decision-makers, is enabled. The advantages are primarily manifested in 
the easily accessible compilation of the data relating to all the aspects of investment planning, and, in this way, data can be processed through the application multicriteria methods, AHP and PROMETHEE, and their synergic effect. It has been shown that the proposed approach is adaptable and provides the possibility to include a variety of stakeholders, regardless of whether they are a single or multi stakeholder, i.e., individuals or groups. A contribution has been made in forming a way to include all opinions into a hierarchical goal structure by determining criteria weights. The AHP method provides a suitable way to do so, giving all the stakeholders, at the same time, the possibility to express their opinions and be a part of the compromise solution. The later PROMETHEE method proved to be a very good choice for priority ranking because it provided a simple insight to all involved during the decision-making process.

The next advantage of the proposed decision support concept for selecting the location of wastewater treatment plants is that this model enables the timely inclusion of all relevant stakeholders (experts, government/investors, citizens) that are required to ensure a high-quality planning process. Especially, this method allows for the inclusion of the opinions of city government throughout every stage of the planning process, whether directly or indirectly, and that is adaptable when conditions are altered and amenable to customizations required by all other stakeholders indirectly. Therefore, this approach to the investment planning in urban management projects, which are important to insure the sustainable development of cities, is particularly valuable during times when other criteria, apart from financial ones, have a significant impact to the outcome of the project.

Author Contributions: The following statements should be used "Conceptualization, N.J., I.M., K.R. and J.K.; Methodology, N.J., I.M., K.R. and J.K.; Software, N.J., I.M., K.R. and J.K.; Validation, N.J., I.M., K.R. and J.K.; Formal Analysis, N.J., I.M., K.R. and J.K.; Investigation, N.J., I.M., K.R. and J.K.; Resources, N.J., I.M., K.R. and J.K.; Data Curation, N.J., I.M., K.R. and J.K.; Writing-Original Draft Preparation, N.J., I.M., K.R. and J.K.; Writing-Review \& Editing, N.J., I.M., K.R. and J.K.; Visualization, N.J., I.M., K.R. and J.K.; Supervision, N.J., I.M., K.R. and J.K.; Project Administration, N.J., I.M., K.R. and J.K.; Funding Acquisition, N.J., I.M., K.R. and J.K."

Funding: This research is partially supported through project KK.01.1.1.02.0027, a project co-financed by the Croatian Government and the European Union through the European Regional Development Fund-the Competitiveness and Cohesion Operational Programme.

Conflicts of Interest: The authors declare no conflict of interest.

\section{References}

1. Dixon, A.; Simon, M.; Burkitt, T. Assessing the environmental impact of two options for small scale wastewater treatment: Comparing a reedbed and an aerated biological filter using a life cycle approach. Ecol. Eng. 2003, 20, 297-308. [CrossRef]

2. Lundin, M.; Bengtsson, M.; Molander, S. Life cycle assessment of wastewater systems: Influence of system boundaries and scale on calculated environmental loads. Environ. Sci. Technol. 2000, 34, 180-186. [CrossRef]

3. Turban, E. Decision Support and Expert System: Management Support System; Macmillan Publishing Company: New York, NY, USA, 1993.

4. Saaty, T.L. The Analytic Hierarchy Process; McGraw-Hill International: New York, NY, USA, 1980.

5. Brans, J.P.; Mareschal, B.; Vincke, P.H. PROMETHEE-a New Family of Outranking Methods in Multicriteria Analysis; Brans, J.P., Ed.; Operational Research IFORS 84; North Holland: Amsterdam, The Netherlands, 1984; pp. 477-490.

6. Macharis, C.; Springael, J.; De Brucker, K.; Verbeke, A. PROMETHEE and AHP: The design of operational synergies in multicriteria analysis. Strengthening PROMETHEE with ideas of AHP. Eur. J. Oper. Res. 2004, 153, 307-317. [CrossRef]

7. Pasqualino, J.; Meneses, M.; Abella, M.; Castells, F. LCA as a Decision Support Tool for the Environmental Improvement of the Operation of a Municipal Wastewater Treatment Plant. Environ. Sci. Technol. 2009, 43, 3300-3307. [CrossRef]

8. Turkova, J.; Korytarova, J. Methods foe evaluation of WWTPs environmental impacts: A review. IOP Conf. Ser. Earth Environ. 2019, 222, 012004. [CrossRef] 
9. Poch, M.; Comas, J.; Rodriguez-Roda, I.; Sànchez-Marrè, M.; Cortés, U. Designing and building real environmental decision support systems. Environ. Model. Softw. 2004, 19, 857-873. [CrossRef]

10. Gernaeya, K.V.; van Loosdrecht, M.C.M.; Henze, M.; Lind, M.; Jørgensen, S.J. Activated sludge wastewater treatment plant modelling and simulation: State of the art. Environ. Model. Softw. 2004, 19, 763-783. [CrossRef]

11. Assaf, H.; Saadeh, M. Assessing water quality management options in the Upper Litani Basin, Lebanon, using an integrated GIS-based decision support system. Environ. Model. Softw. 2008, 23, 1327-1337. [CrossRef]

12. Ceccaroni, L.; Cortés, U.; Sánchez-Marré, M. OntoWEDSS: Augmenting environmental decision-support systems with ontologies. Environ. Model. Softw. 2004, 19, 785-797. [CrossRef]

13. Hidalgo, D.; Irusta, R.; Martinez, L.; Fatta, D.; Papadopoulos, A. Development of a multi-function software decision support tool for the promotion of the safe reuse of treated urban wastewater. Desalination 2007, 215, 90-103. [CrossRef]

14. Garrido-Baserba, M.; Molinos-Senante, M.; Abelleira-Pereira, J.M.; Fdez-Güelfo, L.A.; Poch, M.; Hernandez-Sancho, F. Selecting sewage sludge treatment alternatives in modern wastewater treatment plants using environmental decision support systems. J. Clean. Prod. 2015, 107, 410-419. [CrossRef]

15. Gómez-López, M.D.; Bayob, J.; García-Cascales, M.S.; Angosto, J.M. Decision support in disinfection technologies for treated wastewater reuse. J. Clean. Prod. 2009, 17, 1504-1511. [CrossRef]

16. Hamouda, M.A.; Anderson, W.B.; Huck, P.M. Decision support systems in water and wastewater treatment process selection and design: A review. Water Sci. Technol. 2009, 60, 1757-1770. [CrossRef]

17. Balkema, A.J.; Preisig, H.A.; Otterpohl, R.; Lambert, F.J.D. Indicators for the sustainability assessment of wastewater treatment systems. Urban Water 2002, 4, 153-161. [CrossRef]

18. Okubo, T.; Kubo, K.; Hosomi, M.; Murakami, A. A knowledge-based decision support system for small-scale wastewater treatment processes. Water Sci. Technol. 1994, 30, 175-184. [CrossRef]

19. Alemany, J.; Comas, J.; Turon, C.; Balaguer, M.D.; Poch, M.; Puig, M.A.; Bou, J. Evaluating the application of a decision support system in identifying adequate wastewater treatment for small communities. A case study: The Fluvia River Basin. Water Sci. Technol. 2005, 51, 179-186. [CrossRef]

20. Molinos-Senante, M.; Garrido-Baserba, M.; Reif, R.; Hernández-Sancho, F.; Poch, M. Assessment of wastewater treatment plant design for small communities: Environmental and economic aspects. Sci. Total Environ. 2012, 427-428, 11-18. [CrossRef]

21. Comas, J.; Alemany, J.; Poch, M.; Torrens, A.; Salgot, M.; Bou, J. Development of a knowledge-based decision support system for identifying adequate wastewater treatment for small communities. Water Sci. Technol. 2003, 48, 393-400. [CrossRef]

22. Kallali, H.; Anane, M.; Jellali, S.; Tarhouni, J. GIS-based multi-criteria analysis for potential wastewater aquifer recharge sites. Desalination 2007, 215, 111-119. [CrossRef]

23. Giordano, R.; Passarella, G.; Uricchio, V.F.; Vurro, M. Integrating conflict analysis and consensus reaching in a decision support system for water resource management. J. Environ. Manag. 2007, 84, 213-228. [CrossRef] [PubMed]

24. Belia, E.; Amerlinck, Y.; Benedetti, L.; Johnson, B.; Sin, G.; Vanrolleghem, P.A.; Gernaey, K.V.; Gillot, S.; Neumann, M.B.; Rieger, L.; et al. Wastewater treatment modelling: Dealing with uncertainties. Water Sci. Technol. 2009, 60, 1929-1941. [CrossRef] [PubMed]

25. Paredes, J.; Andreu, J.; Solera, A. A decision support system for water quality issues in the Manzanares River (Madrid, Spain). Sci. Total Environ. 2010, 408, 2576-2589. [CrossRef] [PubMed]

26. Aulinas, M.; Nieves, J.C.; Cortés, U.; Poch, M. Supporting decision making in urban wastewater systems using a knowledge-based approach. Environ. Model. Softw. 2011, 26, 562-572. [CrossRef]

27. Hakanen, J.; Miettinen, K.; Sahlstedt, K. Wastewater treatment: New insight provided by interactive multiobjective optimization. Decis. Support Syst. 2011, 51, 328-337. [CrossRef]

28. Prat, P.; Benedetti, L.; Corominas, L.; Comas, J.; Poch, M. Model-based knowledge acquisition in environmental decision support system for wastewater integrated management. Water Sci. Technol. 2012, 65, 1123-1129. [CrossRef]

29. Willuweit, L.; O'Sullivan, J.J. A decision support tool for sustainable planning of urban water systems: Presenting the Dynamic Urban Water Simulation Model. Water Res. 2013, 47, 7206-7220. [CrossRef] 
30. Li, Y.; Lin, C.; Wang, Y.; Gao, X.; Xie, T.; Hai, R.; Wang, X.; Zhang, X. Multi-criteria evaluation method for site selection of industrial wastewater discharge in coastal regions. J. Clean. Prod. 2017, 161, 1143-1152. [CrossRef]

31. Jajac, N.; Bilić, I.; Ajduk, A. Decision Support Concept to Management of Construction Projects-Problem of Construction Site Selection. Croat. Oper. Res. Rev. 2013, 4, 235-247.

32. Bitunjac, I.; Jajac, N.; Katavic, I. Decision support to sustainable management of bottom trawl fleet. Sustainability 2016, 8, 204. [CrossRef]

33. Marović, I.; Završki, I.; Jajac, N. Ranking zones model-A multicriterial approach to the spatial management of urban areas. Croat. Oper. Res. Rev. 2015, 6, 91-103. [CrossRef]

34. Marović, I.; Hanak, T. Selection of adequate site location during early stages of construction project management: A multi-criteria decision analysis approach. IOP Conf. Ser. Mater. Sci. Eng. 2017, 251. [CrossRef]

35. Rogulj, K.; Jajac, N. Achieving a Construction Barrier-Free Environment: Decision Support to Policy Selection. J. Manag. Eng. 2018, 34, 04018020. [CrossRef]

36. Jajac, N.; Rogulj, K.; Radnić, J. Selection of the Method for Rehabilitation of Historic Bridges-Decision Support Concept for Planning of Rehabilitation Projects. Int. J. Archit. Herit. 2017, 11, 261-277. [CrossRef]

37. Jajac, N.; Marović, I.; Baučić, M. Decision support concept for managing the maintenance of city parking facilities. Electron. J. Fac. Civ. Eng. Osijek-E-Gfos 2014, 9, 60-69. [CrossRef]

38. Mladieno, M.; Jajac, N.; Rogulj, K. A simplified approach to the PROMETHEE method for priority setting in management of mine action projects. Croat. Oper. Res. Rev. 2016, 7, 249-268. [CrossRef]

39. Hazir, O. A review of analytical models, approaches and decision support tools in project monitoring and control. Int. J. Proj. Manag. 2015, 331, 808-815. [CrossRef]

40. Mendoza, G.A.; Macoun, P.; Prabhu, R.; Sukadri, D.; Purnomo, H.; Hartanto, H. Guidelines for Applying Multi-Criteria Analysis to the Assessment of Criteria and Indicators; Center for International Forestry Research (CIFOR): Jakarta, Indonesia, 1999.

41. Brans, J.P.; Vincke, P.H. A preference ranking organization method, the PROMETHEE method for MCDM. Manag. Sci. 1985, 31, 647-656. [CrossRef]

(C) 2019 by the authors. Licensee MDPI, Basel, Switzerland. This article is an open access article distributed under the terms and conditions of the Creative Commons Attribution (CC BY) license (http://creativecommons.org/licenses/by/4.0/). 